Research Paper

\title{
Clock gene Per2 as a controller of liver carcinogenesis
}

\author{
Ali Mteyrek ${ }^{1}$, Elisabeth Filipski ${ }^{1}$, Catherine Guettier ${ }^{2}$, Alper Okyar ${ }^{3}$, Francis Lévi ${ }^{1,2,4}$ \\ ${ }^{1}$ INSERM and Paris Sud University, UMRS 995, Team « Cancer Chronotherapy and Postoperative Liver », Campus CNRS, \\ Villejuif F-94807, France \\ ${ }^{2}$ Assistance Publique-Hopitaux de Paris, Department of Medical Oncology and Laboratory of Anatomy and Pathologic Cytology, \\ Hôpital Paul Brousse, Villejuif F-94800, France \\ ${ }^{3}$ Istanbul University Faculty of Pharmacy, Department of Pharmacology, Beyazit TR-34116, Istanbul, Turkey \\ ${ }^{4}$ Warwick Medical School, Cancer Chronotherapy Unit, Coventry, CV4 7AL, United Kingdom \\ Correspondence to: Francis Lévi, email: F.Levi@warwick.ac.uk
}

Keywords: Circadian rhythm, Per2 gene, Hepatocellular carcinoma, Molecular clock, Cell cycle genes

Received: May 12, 2016

Accepted: July 13, 2016

Published: August 03, 2016

\section{ABSTRACT}

Environmental disruption of molecular clocks promoted liver carcinogenesis and accelerated cancer progression in rodents. We investigated the specific role of clock gene Period 2 (Per2) for liver carcinogenesis and clock-controlled cellular proliferation, genomic instability and inflammation. We assessed liver histopathology, and determined molecular and physiology circadian patterns in mice on chronic diethylnitrosamine (DEN) exposure according to constitutive Per2 mutation. First, we found that Per $2^{\mathrm{m} / \mathrm{m}}$ liver displayed profound alterations in proliferation gene expression, including c-Myc derepression, phase-advanced Wee1, and arrhythmic Ccnb1 and K-ras mRNA expressions, as well as deregulated inflammation, through arrhythmic liver IL- 6 protein concentration, in the absence of any DEN exposure. These changes could then make Per $2^{\mathrm{m} / \mathrm{m}}$ mice more prone to subsequently develop liver cancers on DEN. Indeed, primary liver cancers were nearly fourfold as frequent in Per $2^{\mathrm{m} / \mathrm{m}}$ mice as compared to wild-type (WT), 4 months after DEN exposure. The liver molecular clock was severely disrupted throughout the whole carcinogenesis process, including the initiation stage, i.e. within the initial 17 days on DEN. Per $2^{\mathrm{m} / \mathrm{m}}$ further exhibited increased C-Myc and Ccnb1 mean 24h expressions, lack of P53 response, and arrhythmic ATM, Wee1 and Conb1 expressions. DEN-induced tumor related inflammation was further promoted through increased protein concentrations of liver IL-6 and TNF-a as compared to WT during carcinogenesis initiation. Per2 mutation severely deregulated liver gene or protein expressions related to three cancer hallmarks, including uncontrolled proliferation, genomic instability, and tumor promoting inflammation, and accelerated liver carcinogenesis several-fold. Clock gene Per2 acted here as a liver tumor suppressor from initiation to progression.

\section{INTRODUCTION}

Hepatocellular carcinoma (HCC) is the sixth most frequent cancer and the third most common cause of cancer mortality worldwide [1]. Clock gene Per2 plays a central role in the prominent circadian regulation of liver metabolism and proliferation [2, 3]. Here we aimed at determining the role of Per2 in liver carcinogenesis. To address this question, chronic exposure to diethylnitrosamine (DEN) was used as a model for inducing rodent $\mathrm{HCC}$, whose histology and genetic signature have been considered to be similar to poor prognosis human HCC [4].

Circadian rhythms with an about 24-h period characterize the expression patterns of $10-40 \%$ of mouse liver transcripts $[5,6]$. These molecular rhythms are controlled by a genetic molecular clock in each cell [7]. The molecular oscillator involves an activation loop, where Clock or NPas 2 and Bmall activate the transcription of Period (Per) genes 1, 2 and 3, Cryptochrome (Cry) genes $1 / 2$, Rev-erb $\alpha / \beta$ and Dec 1/2. In turn, the Per, Cry, Rev-erb and Dec genes inhibit their own transcription and 
that of other clock genes through the interaction of their protein heterodimers with the CLOCK::BMAL1 protein heterodimer or clock gene promoters [8]. Circadian clocks regulate nutrient and xenobiotic metabolism, immune response, cell division cycle, and cell death and survival $[5,6,9,10]$. Messenger RNA (mRNA) and protein expression rhythms have been identified in mammalian tissues, in cell populations and in single cells $[8,11]$. The molecular rhythms are redundantly controlled by both genetic circadian clocks and physiological rhythms, which build up the Circadian Timing System (CTS) [7, 12]. Mammalian CTS coordination and adjustment to environmental cycles is insured by the suprachiasmatic nuclei (SCN), a neuronal pacemaker located in the anterior hypothalamus [8].

Clock gene Per2 is robustly and rhythmically expressed in liver and almost all mammalian tissues [13]. In vitro studies showed that Per2 overexpression in malignant cells was associated with decreased cell proliferation and increased apoptosis resulting from $P 53$ up-regulation and the down-regulation of Cyclin B1 (CCNB1), B-cell lymphoma 2 (Bcl2) and c-Myc [14-16].

Mice with constitutive Per2 mutation $\left(P e r 2^{\mathrm{m} / \mathrm{m}}\right)$ were produced with a deletion in the PAS domain of Per2 gene, and have been maintained by breeding [17]. The $\operatorname{Per} 2^{\mathrm{m} / \mathrm{m}}$ mice, displayed an alteration of the regulatory molecular circadian clock circuitry, resulting from a rapidly degraded non-functional PER2 protein, as well as decreased apoptosis and accelerated cell cycling [18]. This might account for $P e r 2^{\mathrm{m} / \mathrm{m}}$ mice developing more spontaneous and gamma-radiation-induced cancers [18, 19], and displaying enhanced susceptibility to anticancer chemotherapy [20]. Moreover, oncogene $c-M y c$ was upregulated, while $P 53$ was down regulated in the liver of both $P e r 2^{\mathrm{m} / \mathrm{m}}$ [18] and mice on chronic jet lag, with ablated Per 2 circadian transcription in liver [21] This could explain the significant increase of DEN-induced liver cancers in mice or rats exposed to constant light or iterative shifts in light-dark cycles [22, 23]. DEN carcinogenesis first involves the occurrence of dysplastic foci with altered hepatocytes. Such reversible "initiation" stage of experimental liver carcinogenesis occurs during the initial 2-4 weeks of exposure [24-26]. The hyperplastic foci then develop into neoplastic hepatocellular carcinoma nodules, following exposure to a promoter agent, or continued DEN administration for an additional 4-8 weeks $[25,26]$. Liver cancer nodules subsequently progress.

Here we show that Per 2 mutation fostered three critical liver cancer hallmarks, during the initiation stage. DEN further profoundly disrupted the circadian timing system during the promotion stage. This effect was most prominent in Per $2^{\mathrm{m} / \mathrm{m}}$ mice, with a further deterioration during the progression stage. Overall, Per2 loss-of-function resulted in a fourfold increase in DENinduced hepatocarcinoma nodules as compared to clockproficient mice.

\section{RESULTS}

\section{Per2 control of selected liver carcinogenesis pathways}

The regulatory role of clock gene Per2 was first investigated for circadian clock, proliferation, genomic instability, and inflammation, through comparing selected gene or protein circadian expressions in the liver of WildType (WT) and $P e r 2^{\mathrm{m} / \mathrm{m}}$ mice. Samples were obtained in non-DEN exposed animals at 6 different time points, located $4 \mathrm{~h}$ apart.

The mRNA expression of core clock gene Bmal1 displayed marked and statistically significant $24 \mathrm{~h}$ changes both in WT and $P e r 2^{\mathrm{m} / \mathrm{m}}$ mice (Figure 1A). This was also the case for all other clock genes including Rev-erb $\alpha$, Clock, Cry1, and Cry2 (Supplementary Figure S1A). Circadian rhythms with $\tau=24 \mathrm{~h}$ were validated with Cosinor for each clock gene expression in each genotype, except for Clock in $P e r 2^{\mathrm{m} / \mathrm{m}}$. Yet, circadian transcription of Bmal1, Rev-erbo, Cry1, and Cry 2 were phase-advanced by 2- to 5-h, and circadian amplitudes of Bmall, Reverbo, and Cryl were dampened by $19 \%$ to $59 \%$ in $P e r 2^{\mathrm{m} / \mathrm{m}}$ as compared to WT mice (Hotelling t-tests for phase and amplitude comparisons, $p<0.001$ for each gene) (Supplementary Figure S1A; Table 1).

The phase advance and amplitude dampening in the liver clock of $P e r 2^{\mathrm{m} / \mathrm{m}}$ translated into a 2-3 h phase advance of $c-M y c$ (Figure 1B) and Weel circadian rhythms (Hotelling t-test, $p<0.05$ ), and the suppression of the Ccnb1 and K-ras $24 \mathrm{~h}$ rhythms as compared to WT mice (Figure 1B, Supplementary Figure S1B, Table 1). ATM expression displayed a similar circadian rhythm with a maximum at ZT9 and a trough at ZT19 in both genotypes. In addition, the 24-h mean mRNA expression was significantly decreased for $P 53$, increased for $\mathrm{Bcl}-2$ and doubled for $c-M y c$ in $P e r 2^{\mathrm{m} / \mathrm{m}}$ as compared to WT mice (ANOVA, $p \leq 0.001$ ) (Figure 1B, Table 1).

Liver IL-6 protein concentration displayed a circadian pattern in WT with a maximum at ZT11 (Cosinor analysis, $p=0.04$ ), but no such rhythm was found in $P e r 2^{\mathrm{m} / \mathrm{m}}$ mice $(p=0.17)$ (Supplementary Figure S1C). The 24-h mean concentration of liver IL6 was increased in $P e r 2^{\mathrm{m} / \mathrm{m}}$, although not significantly so $(p=0.09)$. No circadian change was found for liver TNF- $\alpha$ concentration in either genotype, yet the 24-h mean level was decreased in $P e r 2^{\mathrm{m} / \mathrm{m}}$ as compared to WT mice $(p=0.017)$ (Figure $1 \mathrm{C}$, Table 1).

\section{Relevance of clock gene Per2 for liver carcinogenesis initiation processes}

Here, the role of Per2 was investigated on both liver pathology and selected molecular biomarkers during the initiation stage of liver carcinogenesis. WT and $P e r 2^{\mathrm{m} / \mathrm{m}}$ mice received daily DEN (15 mg/kg ip) for 5 days a week 

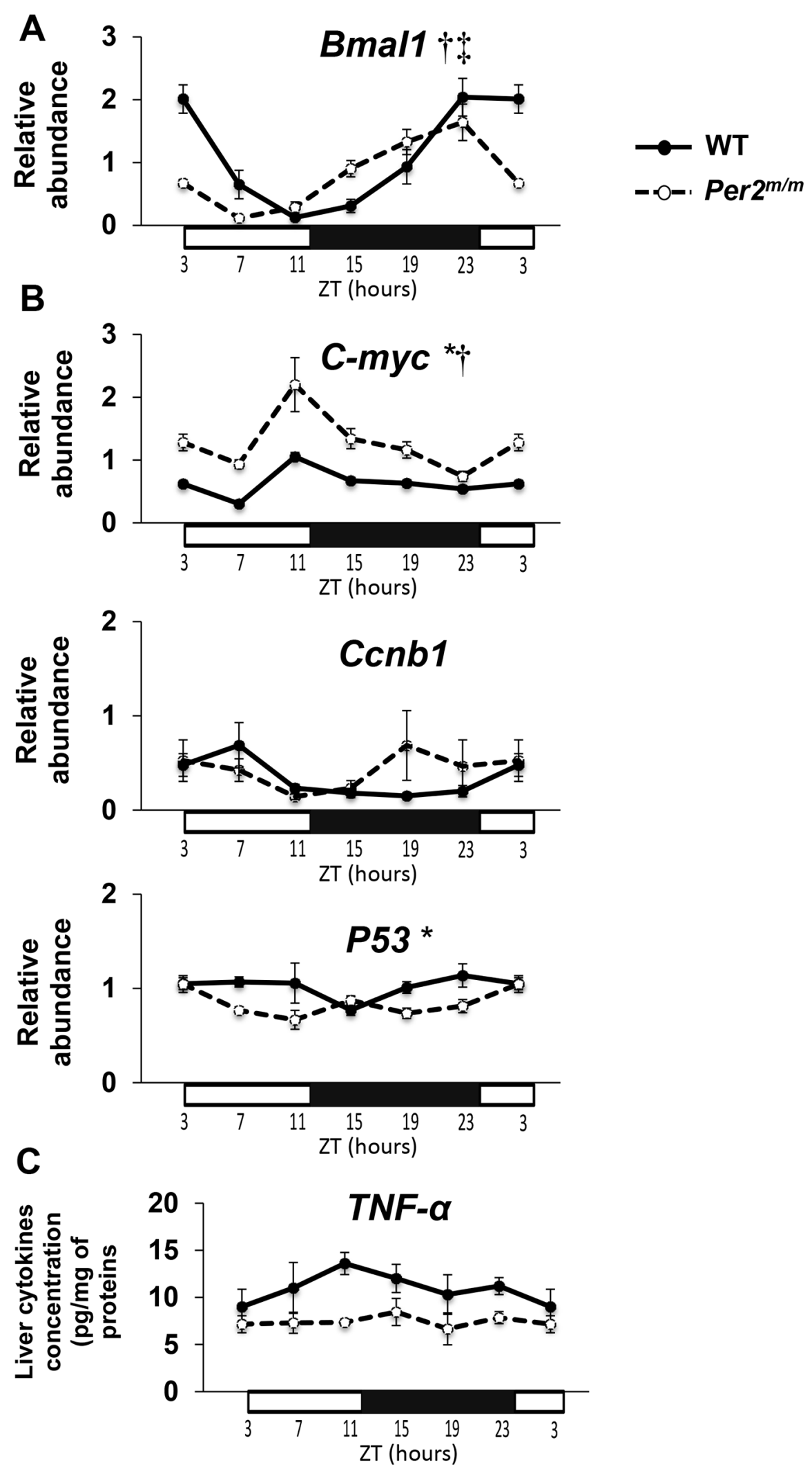

Figure 1: Moderation of selected liver clock, proliferation, genomic instability and pro-inflammatory cytokine patterns by Per2 loss-of-function. Each data point is mean of 5 mice at each of 6 Zeitgeber Times (ZT) for WT (dark circles) or Per $2^{\mathrm{m} / \mathrm{m}}$ mice (open circles). Circadian changes in mean \pm SEM of mRNA expression for A. clock gene Bmall; B. proliferation and genomic instability genes $c-M y c, C c n b 1$, and P53; C. TNF- $\alpha$ protein concentration in liver. Results from 2 -way ANOVA: * $p$ (genotype $) \leq 0.01 ; \uparrow p(\mathrm{ZT}) \leq 0.01$; $\$ p$ (interaction) $\leq 0.01$. 
Table 1: Circadian rhythms of selected gene mRNA expressions and cytokine concentrations in the liver of control WT and $P e r 2^{\mathrm{m} / \mathrm{m}}$ mice in the absence of any DEN exposure (Results from cosinor analysis with $\tau=24 \mathrm{~h}$ )

\begin{tabular}{|c|c|c|c|c|c|c|}
\hline Function & Gene & Genotype & $p$ & Mesor $[95 \% \mathrm{CL}]$ & $\begin{array}{c}\text { Amplitude }[95 \% \\
\text { CL }]\end{array}$ & $\begin{array}{c}\text { Acrophase, } \mathrm{ZT}: \text { min } \\
{[95 \% \mathrm{CL}]}\end{array}$ \\
\hline \multirow{10}{*}{ Clock } & \multirow{2}{*}{ Clock } & WT & $<0.001$ & $1.03[0.91$ to 1.15$]$ & $0.56[0.38$ to 0.73$]$ & $23: 35[22: 20$ to $00: 45]$ \\
\hline & & $\operatorname{Per} 2^{\mathrm{m} / \mathrm{m}}$ & 0.13 & $0.97[0.83$ to 1.1$]$ & 0.19 & $22: 25$ \\
\hline & \multirow{2}{*}{ Bmal1 } & WT & $<0.001$ & 1.02 [0.84 to 1.19$]$ & $1.04[0.8$ to 1.28$]$ & $00: 30[23: 30$ to $1: 30]$ \\
\hline & & $\operatorname{Per} 2^{\mathrm{m} / \mathrm{m}}$ & $<0.001$ & $0.82[0.69$ to 0.96$]$ & $0.74[0.55$ to 0.94$]$ & $20: 45[19: 45$ to $21: 45]$ \\
\hline & \multirow{2}{*}{$\begin{array}{l}\text { Rev- } \\
\text { erba }\end{array}$} & WT & $<0.001$ & $0.86[0.46$ to 1.25$]$ & $1.24[0.79$ to 1.72$]$ & $8: 05[6: 20$ to $9: 55]$ \\
\hline & & $\operatorname{Per} 2^{\mathrm{m} / \mathrm{m}}$ & $<0.001$ & $1.04[0.82$ to 1.25$]$ & $1.01[0.7$ to 1.31$]$ & $5: 00[3: 50$ to $6: 10]$ \\
\hline & \multirow{2}{*}{ Cryl } & WT & $<0.001$ & $1.25[0.99$ to 1.51$]$ & $1.07[0.71$ to 1.43$]$ & $21: 50[20: 30$ to $23: 10]$ \\
\hline & & $\operatorname{Per} 2^{\mathrm{m} / \mathrm{m}}$ & $<0.001$ & $0.82[0.7$ to 0.94$]$ & $0.44[0.27$ to 0.61$]$ & $16: 40[15: 10$ to $18: 10]$ \\
\hline & \multirow{2}{*}{ Cry2 2} & WT & 0.04 & $1[0.85$ to 1.15$]$ & $0.25[0.02$ to 0.48$]$ & $13: 35[9: 20$ to $17: 40]$ \\
\hline & & $\operatorname{Per} 2^{\mathrm{m} / \mathrm{m}}$ & 0.04 & $1.05[0.93$ to 1.17$]$ & $0.22[0.05$ to 0.39$]$ & $11: 40[8: 25$ to $15: 00]$ \\
\hline \multirow{6}{*}{$\begin{array}{l}\text { Genome } \\
\text { instability }\end{array}$} & \multirow{2}{*}{ P53 } & WT & 0.23 & $1.01[0.91$ to 1.11$]$ & 0.12 & $3: 00$ \\
\hline & & $\operatorname{Per} 2^{\mathrm{m} / \mathrm{m}}$ & 0.15 & $0.81[0.74$ to 0.88$]$ & 0.09 & $1: 30$ \\
\hline & \multirow{2}{*}{$\mathrm{Bcl} 2$} & WT & 0.19 & $0.71[0.62$ to 0.81$]$ & 0.12 & $5: 10$ \\
\hline & & $\operatorname{Per} 2^{\mathrm{m} / \mathrm{m}}$ & 0.63 & $0.98[0.82$ to 1.14$]$ & 0.1 & $22: 40$ \\
\hline & \multirow{2}{*}{$A T M$} & WT & 0.02 & $1.16[1.04$ to 1.29$]$ & $0.25[0.08$ to 0.42$]$ & $9: 00[6: 00$ to $12: 00]$ \\
\hline & & $\operatorname{Per} 2^{\mathrm{m} / \mathrm{m}}$ & $<0.001$ & 1.22 [1.12 to 1.32$]$ & $0.34[0.19$ to 0.49$]$ & $8: 20[6: 30$ to $10: 10]$ \\
\hline \multirow{8}{*}{ Proliferation } & \multirow{2}{*}{ Weel } & WT & $<0.001$ & $1.24[0.98$ to 1.50$]$ & $1.02[0.65$ to 1.38$]$ & $13: 20[12: 00$ to $14: 40]$ \\
\hline & & $\operatorname{Per} 2^{\mathrm{m} / \mathrm{m}}$ & $<0.001$ & $1.34[1.15$ to 1.52$]$ & $1.12[0.86$ to 1.38$]$ & $10: 00[9: 00$ to $11: 00]$ \\
\hline & \multirow{2}{*}{ Ccnbl } & WT & 0.004 & $0.32[0.23$ to 0.41$]$ & $0.24[0.11$ to 0.37$]$ & $5: 40[3: 25$ to $7: 40]$ \\
\hline & & $\operatorname{Per} 2^{\mathrm{m} / \mathrm{m}}$ & 0.25 & $0.41[0.24$ to 0.58$]$ & 0.19 & $23: 20$ \\
\hline & \multirow{2}{*}{$c-M y c$} & WT & 0.046 & $0.64[0.54$ to 0.74$]$ & $0.17[0.04$ to 0.3$]$ & $13: 40[10: 20$ to $17: 00]$ \\
\hline & & $\operatorname{Per} 2^{\mathrm{m} / \mathrm{m}}$ & 0.038 & $1.27[1.02$ to 1.52$]$ & $0.46[0.11$ to 0.81$]$ & $11: 40[8: 25$ to $15: 00]$ \\
\hline & \multirow{2}{*}{$K$-ras } & WT & 0.009 & $0.82[0.72$ to 0.92$]$ & $0.24[0.09$ to 0.38$]$ & $23: 20[20: 50$ to $25: 50]$ \\
\hline & & $\operatorname{Per} 2^{\mathrm{m} / \mathrm{m}}$ & 0.31 & $0.69[0.6$ to 0.78$]$ & 0.09 & $8: 40$ \\
\hline \multirow{4}{*}{ Inflammation } & \multirow{2}{*}{ IL-6 } & WT & 0.04 & $6.72[5.8$ to 7.64$]$ & $1.7[0.4$ to 3$]$ & $12: 15[8: 50$ to $15: 40]$ \\
\hline & & $\operatorname{Per} 2^{\mathrm{m} / \mathrm{m}}$ & 0.17 & $7.55[7.14$ to 7.96$]$ & 0.55 & $10: 00$ \\
\hline & \multirow{2}{*}{$\mathrm{TNF}-\alpha$} & WT & 0.29 & 9.3 [8.1 to 10.5$]$ & 1.3 & $12: 45$ \\
\hline & & $\operatorname{Per} 2^{\mathrm{m} / \mathrm{m}}$ & 0.93 & 7.456 .52 to 8.38 & 0.25 & $14: 20$ \\
\hline
\end{tabular}

over a 17 day-span (cumulative dose of $195 \mathrm{mg} / \mathrm{kg}$ ). Liver samples were obtained in DEN-exposed animals at 6 different time points, located $4 \mathrm{~h}$ apart.

\section{Pathology findings}

After being on DEN for 17 days, mice displayed few hepatic lesions associated with inflammatory foci and some apoptotic and necrotic cells. The histological features were supportive of early stage carcinogenesis processes, yet no gross difference was apparent between WT and $P e r 2^{\mathrm{m} / \mathrm{m}}$ mice.

\section{Twenty-four hour patterns in selected gene expressions}

The circadian transcription patterns of the genes studied after a 17-day exposure to DEN differed markedly according to Per2 mutation (Figure 2, Supplementary Figure S2). The mRNA expression of clock genes Bmall, Rev-erbo, Clock, Cry1, and Cry2 exhibited statistically 
significant circadian variations for both WT and Per $2^{\mathrm{m} / \mathrm{m}}$ mice (2-way ANOVA: ZT effect, $p<0.001$; Cosinor, $p<$ 0.03 to $p<0.001)$. The rhythms were phase advanced by 5 h for Bmall (Figure 2A), by $4 \mathrm{~h}$ for Clock, Cryl and Cry2, and by $7 \mathrm{~h}$ for Rev-erbo in $P e r 2^{\mathrm{m} / \mathrm{m}}$ as compared to WT (Supplementary Figure S2A, $p<0.001$ for each gene). The circadian amplitudes of clock genes were also reduced by 34 to $74 \%$ except for Cry2 in Per2 ${ }^{\mathrm{m} / \mathrm{m}}$ compared to WT ( $p$ $<0.001$ ) (Supplementary Figure S2A, Table 2).
Twenty four-hour changes were also statistically validated for the proliferation genes $c-M y c$, as wells as Wee 1, Ccnb1, and K-ras, and for the genomic instability genes P53, ATM, and Bcl2 (Figure 2B, Supplementary Figure S2B) (2-way ANOVA: ZT effect, $p<0.01$ for each gene). Circadian rhythms were validated with Cosinor for Wee1, Ccnb1, K-ras, ATM, and P53 in WT mice $(p<0.05$ to $p<0.001)$, but only for K-ras in $P e r 2^{\mathrm{m} / \mathrm{m}}(p=0.006)$, while 12-h rhythms were found for $c-M y c$ in both for
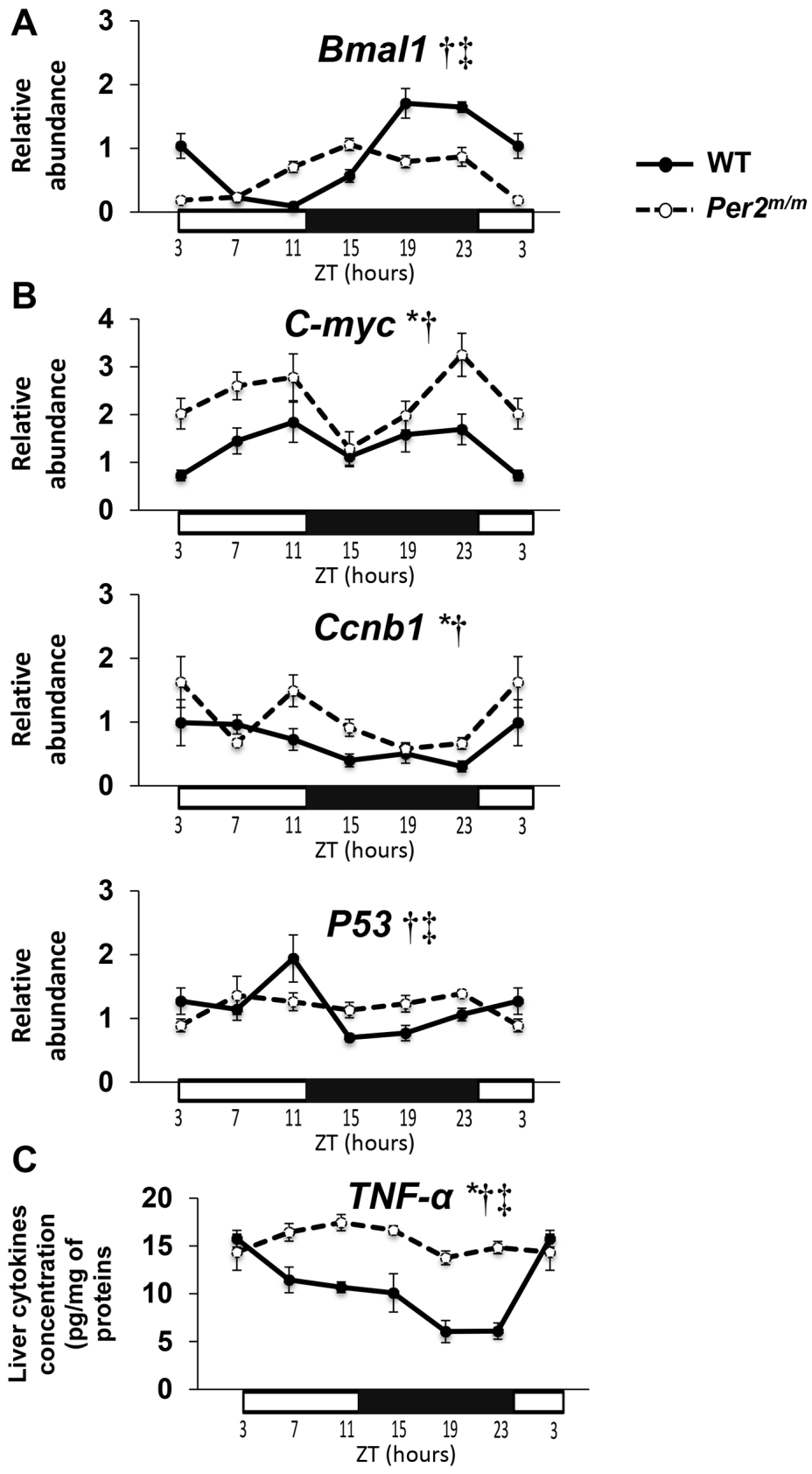

Figure 2: Circadian gene or protein expressions during initiation phase of carcinogenesis. Each data point is mean of 5-7 mice at each of 6 Zeitgeber Times (ZT) for WT (dark circles) or Per $2^{\mathrm{m} / \mathrm{m}}$ mice (open circles). Circadian changes in mean \pm SEM of mRNA expression for A. clock gene Bmall; B. proliferation and genomic instability genes $c-M y c, C c n b 1$, and P53; C. TNF- $\alpha$ protein concentration in liver. Results from 2-way ANOVA: * $p$ (genotype $) \leq 0.01 ; \uparrow p(\mathrm{ZT}) \leq 0.01 ;+p($ interaction $) \leq 0.01$. 
Table 2: Circadian rhythms of selected gene mRNA expressions and cytokine concentrations in the liver of WT and $P e r 2^{\mathrm{m} / \mathrm{m}}$ mice exposed to DEN over 17 days (Results from cosinor analysis with $\boldsymbol{\tau}=\mathbf{2 4 h}$ )

\begin{tabular}{|c|c|c|c|c|c|c|}
\hline Function & Gene & Genotype & $p$ & Mesor $[95 \% \mathrm{CL}]$ & Amplitude $[95 \%$ CL] & $\begin{array}{c}\text { Acrophase, ZT : min } \\
{[95 \% \text { CL] }}\end{array}$ \\
\hline \multirow{10}{*}{ Clock } & \multirow{2}{*}{ Clock } & WT & $<0.001$ & $0.96[0.89$ to 1.03$]$ & $0.41[0.29$ to 0.53$]$ & $21: 50[20: 40$ to $23: 00]$ \\
\hline & & $\operatorname{Per} 2^{m / m}$ & $<0.001$ & $0.85[0.77$ to 0.93$]$ & $0.27[0.15$ to 0.39$]$ & $17: 40[15: 55$ to $19: 25]$ \\
\hline & \multirow{2}{*}{ Bmall } & WT & $<0.001$ & $0.87[0.76$ to 0.98$]$ & $0.89[0.73$ to 1.05$]$ & $21: 45[21: 00$ to $22: 30]$ \\
\hline & & $\operatorname{Per} 2^{m / m}$ & $<0.001$ & $0.64[0.55$ to 0.73$]$ & $0.42[0.3$ to 0.54$]$ & $17: 00[15: 50$ to $18: 10]$ \\
\hline & \multirow{2}{*}{ Rev-erb $\alpha$} & WT & $<0.001$ & $0.74[0.57$ to 0.91$]$ & $0.85[0.61$ to 1.09$]$ & $7: 20[6: 20$ to $8: 20]$ \\
\hline & & $\operatorname{Per} 2^{m / m}$ & $<0.001$ & $0.71[0.63$ to 0.79$]$ & $0.39[0.28$ to 0.5$]$ & $00: 10[23: 10$ to $1: 10]$ \\
\hline & \multirow{2}{*}{ Cryl } & WT & $<0.001$ & $1[0.88$ to 1.12$]$ & $1.03[0.86$ to 1.2$]$ & $20: 30[19: 50$ to $21: 10]$ \\
\hline & & $\operatorname{Per} 2^{m / m}$ & $<0.001$ & $0.49[0.43$ to 0.55$]$ & $0.27[0.19$ to 0.35$]$ & $16: 40[15: 30$ to $17: 50]$ \\
\hline & \multirow{2}{*}{ Cry 2} & WT & 0.03 & $0.93[0.84$ to 1.02$]$ & $0.17[0.05$ to 0.29$]$ & $9: 10[6: 00$ to $12: 20]$ \\
\hline & & $\operatorname{Per} 2^{m / m}$ & $<0.001$ & $0.84[0.78$ to 0.90$]$ & $0.18[0.1$ to 0.26$]$ & $5: 35[3: 45$ to $7: 35]$ \\
\hline \multirow{6}{*}{$\begin{array}{l}\text { Genome } \\
\text { instability }\end{array}$} & \multirow{2}{*}{ P53 } & WT & 0.04 & 1.14 [0.94 to 1.34$]$ & $0.38[0.1$ to 0.66$]$ & $7: 40[4: 20$ to $11: 00]$ \\
\hline & & $\operatorname{Per} 2^{m / m}$ & 0.91 & $1.02[1.06$ to 1.34$]$ & 0.04 & $14: 45$ \\
\hline & \multirow{2}{*}{ Bcl2 } & WT & 0.08 & $0.93[0.78$ to 1.08$]$ & 0.26 & $22: 50$ \\
\hline & & $\operatorname{Per} 2^{m / m}$ & 0.06 & $1.11[1$ to 1.22$]$ & 0.2 & $23: 30$ \\
\hline & \multirow{2}{*}{$A T M$} & WT & 0.007 & $1.12[0.99$ to 1.25$]$ & $0.32[0.14$ to 0.5$]$ & $18: 50[16: 30$ to $21: 10]$ \\
\hline & & $\operatorname{Per} 2^{m / m}$ & 0.32 & $1.06[0.94$ to 1.18$]$ & 0.12 & $18: 50$ \\
\hline \multirow{8}{*}{ Proliferation } & \multirow{2}{*}{ Weel } & WT & 0.009 & 0.97 [0.78to 1.17$]$ & $0.42[0.14$ to 0.70$]$ & $13: 10[10: 40$ to $15: 40]$ \\
\hline & & $\operatorname{Per} 2^{m / m}$ & 0.09 & $1.15[0.95$ to 1.35$]$ & 0.31 & $5: 10$ \\
\hline & \multirow{2}{*}{ Ccnbl } & WT & 0.02 & $0.64[0.48$ to 0.8$]$ & $0.33[0.11$ to 0.55$]$ & $6: 40[3: 40$ to $9: 40]$ \\
\hline & & $\operatorname{Per} 2^{m / m}$ & 0.19 & $0.99[0.77$ to 1.21$]$ & 0.28 & $7: 00$ \\
\hline & \multirow{2}{*}{$c-M y c$} & WT & 0.79 & $1.4[1.12$ to 1.68$]$ & 0.13 & $15: 30$ \\
\hline & & $\operatorname{Per} 2^{m / m}$ & 0.43 & $2.33[1.95$ to 2.71$]$ & 0.34 & $3: 20$ \\
\hline & \multirow{2}{*}{$K$-ras } & WT & $<0.001$ & $0.88[0.78$ to 0.97$]$ & $0.39[0.25$ to 0.52$]$ & $21: 20[19: 50$ to $22: 40]$ \\
\hline & & $\operatorname{Per} 2^{m / m}$ & 0.006 & $0.84[0.73$ to 0.94$]$ & $0.26[0.11$ to 0.41$]$ & $19: 00[16: 30$ to $21: 30]$ \\
\hline \multirow{4}{*}{ Inflammation } & \multirow{2}{*}{ IL-6 } & WT & 0.001 & $7.9[7.1$ to 8.7$]$ & $2.36[1.18$ to 3.54$]$ & $10: 25[8: 30$ to $12: 20]$ \\
\hline & & $\operatorname{Per} 2^{m / m}$ & $<0.001$ & $9.5[8.9$ to 10.1$]$ & $1.7[0.9$ to 2.5$]$ & $12: 00[10: 00$ to $14: 00]$ \\
\hline & \multirow{2}{*}{ TNF- $\alpha$} & WT & 0.004 & 10 [8.6 to 11.4$]$ & $3.5[1.5$ to 5.5$]$ & $6: 40[4: 30$ to $8: 50]$ \\
\hline & & $\operatorname{Per} 2^{m / m}$ & 0.023 & 15.57 [14.73 to 16.41$]$ & $1.7[0.5$ to 2.9$]$ & $10: 45[7: 50$ to $13: 40]$ \\
\hline
\end{tabular}

WT and $P e r 2^{\mathrm{m} / \mathrm{m}}$ ( $p=0.02$ and $p=0.005$, respectively), as well as for Weel, Ccnb1, ATM, Bcl-2 in Per2 ${ }^{\mathrm{m} / \mathrm{m}}(p \leq 0.03$ for each gene). Per2 mutation was also associated with increased daily average mRNA expression of $c-M y c$ by $66 \%, C c n b 1$ by $55 \%$, and $B c l-2$ by $20 \%$ ( $p<0.04$ to $p<0.001$ ) (Figure 2B, Table 2).

Liver IL-6 and TNF- $\alpha$ concentrations displayed marked 24-h changes in both genotypes (2-way ANOVA: ZT effect, $p<0.001$; Cosinor with $\tau=24 h, p=0.02$ to $<0.001$ ) (Figure $2 \mathrm{C}$, Supplementary Figure S2C,
Table 2). Both mean IL-6 and TNF- $\alpha$ concentrations were significantly increased in $P e r 2^{\mathrm{m} / \mathrm{m}}$ as compared to $W T$ ( $p=0.003$ and $p<0.001$, respectively).

\section{DEN-induced changes during carcinogenesis initiation according to Per2 mutation}

Overall, the 17-day exposure to DEN markedly altered the circadian gene expression patterns, and did more so in the $P e r 2^{\mathrm{m} / \mathrm{m}}$. In WT mice, DEN phase-advanced 
the mRNA expression patterns of the five clock genes and that of $K$-ras by 1 to $4 \mathrm{~h}$, and nearly inverted the ATM rhythm, as compared to untreated controls (Hotelling t-test for phases: $p=0.01$ to $p<0.001)$. DEN dampened the circadian amplitude of Bmal1, Rev-erbo, Clock, Cry 2 and Weel by 15 to $59 \%$ and amplified the 24-h rhythms of Ccnb1, K-Ras and ATM by 28 to $63 \%$ (Hotelling t-test for amplitude: $p=0.04$ to $p<0.001$ ) (Figures 1 and 2, and left panels in Supplementary Figures S1 and S2).

In $P e r 2^{\mathrm{m} / \mathrm{m}}$, DEN treatment for 17 days phaseadvanced the 24-h rhythms in Bmall, Rev-erb $\alpha$ and Cry 2 by 4 to 6 hours (Hoteling t-test for phases, $p<$ 0.001 ), shortened the rhythm period from $24 \mathrm{~h}$ to 12 $\mathrm{h}$ for $c-M y c$, Weel and Ccnb1, and induced a 24-h rhythm for $K$-ras ( $p=0.03$ to $p=0.005$ ) as compared to untreated Per $2^{\mathrm{m} / \mathrm{m}}$ controls. The $24 \mathrm{~h}$ amplitude was reduced by $43 \%$ for Bmall, 61\% for Rev-erb $\alpha$ and $39 \%$ for Cryl as compared to untreated controls (Hotelling t-test for amplitudes: $p<0.001$ for each gene) (Figures 1 and 2, and right panels in Supplementary Figures S1 and S2).

DEN exposure significantly reduced the 24-h mean expression of Bmal1, Rev-erbo, Cryl and Cry 2 by 20 to $40 \%$ in $P e r 2^{\mathrm{m} / \mathrm{m}}$ and only that of Cry 1 by $20 \%$ in WT. In contrast, DEN exposure nearly doubled the 24-h mean expression of $c-M y c$ and that of Ccnbl both in WT and $P e r 2^{\mathrm{m} / \mathrm{m}}$ with regard to their respective controls $(p<0.05$ to $p<0.001)$ (Table 2$)$.

\section{Severe circadian disruption during carcinogenesis initiation stage in $\mathrm{Per}^{\mathrm{m} / \mathrm{m}}$ on DEN}

The rest-activity and temperature circadian patterns were monitored using implanted telemetry sensors in WT and Per $2^{\mathrm{m} / \mathrm{m}}$ mice for 17 days before DEN exposure, and throughout the 17-day DEN-initiation stage of liver carcinogenesis. The circadian rhythm in plasma corticosterone was determined at completion of this initiation stage in DEN-treated mice and in untreated controls.

Both rest-activity and body temperature patterns were markedly dampened during DEN exposure with more severe apparent alteration in $P e r 2^{\mathrm{m} / \mathrm{m}}$ as compared to WT over the 17-days of DEN exposure (Figure 3A).

Cosinor analysis documented an acrophase advance by nearly $2 \mathrm{~h}$ and $30 \mathrm{~min}$ in $P e r 2^{\mathrm{m} / \mathrm{m}}$ for both rest-activity (ZT17:00 vs ZT19:20, $p=0.014$ ) and body temperature
A
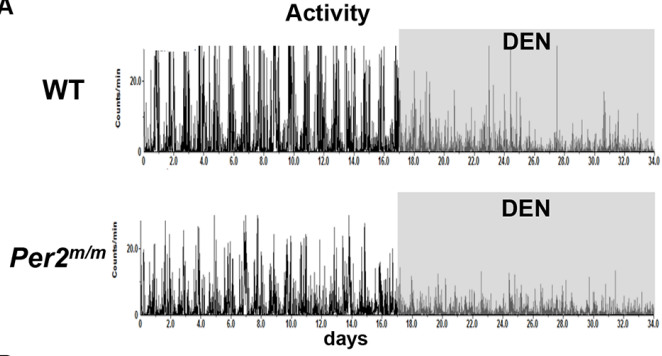

B

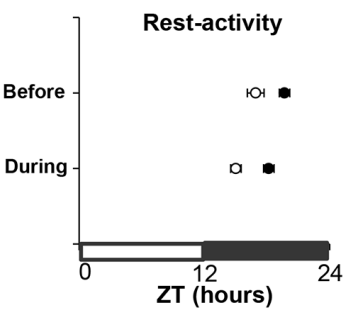

D

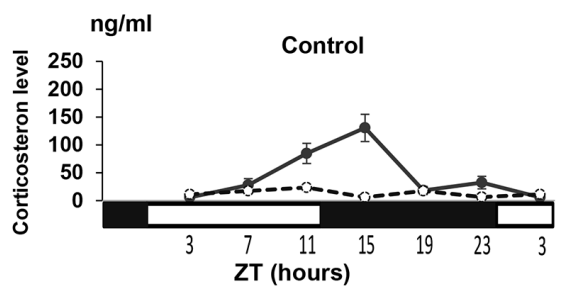

C
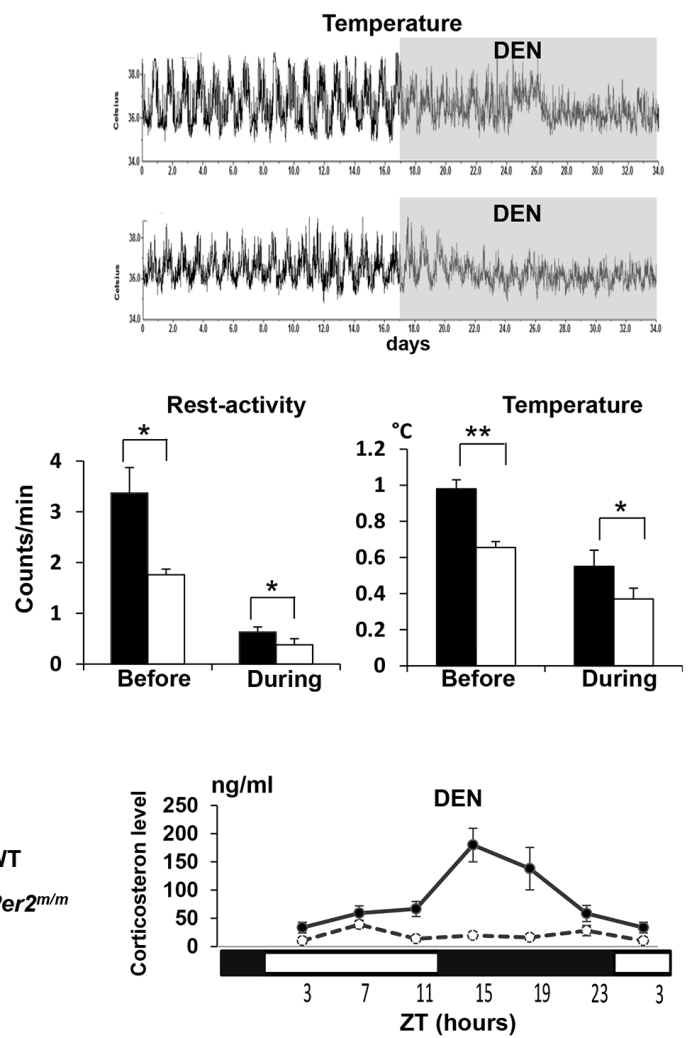

Figure 3: DEN effects during initiation phase on circadian rhythms in rest-activity, body temperature and corticosterone rhythms according to Per 2 mutation during early carcinogenesis. A. Chronograms of telemetered rest-activity (left) and body temperature (right) in WT and $P e r 2^{\mathrm{m} / \mathrm{m}}$ before and during daily DEN exposure for 17 days. B. Corresponding mean circadian acrophases in WT (dark circles) and Per $2^{\mathrm{m} / \mathrm{m}}$ (open circles). C. Corresponding mean circadian amplitudes in WT (dark boxes) and Per $2^{\mathrm{m} / \mathrm{m}}$ (open boxes). D. Twenty-four hour changes in mean plasma corticosterone concentration ( \pm SEM) in untreated WT and Per2 ${ }^{\mathrm{m} / \mathrm{m}}$ mice (left panel) and in WT and $P e r 2^{\mathrm{m} / \mathrm{m}}$ mice after a 17 -day DEN exposure (right panel). ${ }^{*} p<0.05,{ }^{* *} p<0.01$. 
(ZT16:50 vs ZT19:30, $p=0.015$ ) as compared to WT mice, before DEN administration (Figure 3B). The circadian amplitude was nearly halved for rest-activity $(p=0.03)$ and reduced by nearly $40 \%$ for body temperature $(p=0.009)$ in $P e r 2^{\mathrm{m} / \mathrm{m}}$ as compared to WT mice (Figure 3C). DEN exposure did not modify the circadian temperature acrophases, yet it induced $1-\mathrm{h}$ phase advance for rest-activity in WT and a 2-h phase advance in $P e r 2^{\mathrm{m} / \mathrm{m}}$ (Hotelling t-test for phase comparisons, $p=0.004$ ) (Figure 3B).

DEN reduced the circadian amplitude of restactivity by nearly 5.3 -fold and 4.6-fold in WT and $P e r 2^{\mathrm{m} / \mathrm{m}}$ respectively (Hotelling t-test, $p=0.03$ ) and halved that of temperature in both groups (Hotelling t-test for amplitudes, $p=0.02$ ) (Figure 3C).

Plasma corticosterone was rhythmic in WT mice (Cosinor, $p<0.001$ ), but not in Per $2^{\mathrm{m} / \mathrm{m}}$ both in untreated controls and in mice exposed to DEN, with 4.3-fold lower 24-h mean corticosterone levels in treated $P e r 2^{\mathrm{m} / \mathrm{m}}$ as compared to WT $(p<0.001)$ (Figure 3D).

\section{Liver carcinogenesis according to Per2 mutation}

Subsequently, the role of Per2 was investigated regarding $\mathrm{DEN}$-induced liver carcinogenesis from initiation to promotion and progression. WT and Per $2^{\mathrm{m} / \mathrm{m}}$ mice received daily DEN (15 $\mathrm{mg} / \mathrm{kg}$ ip) for 5 days per week over 12 days followed with a 9-day DEN-free span. This allowed for the recovery from sustained body weight loss, during this initiation carcinogenesis stage (cumulative dose $=150 \mathrm{mg} / \mathrm{kg}$ ) (Figure $4 \mathrm{~A})$. A reduced dose of DEN (12 $\mathrm{mg} / \mathrm{kg} /$ day) was then administered according to the same 5-days on/2-days off schedule over 29 days during this promotion stage (cumulative dose $=252 \mathrm{mg} / \mathrm{kg}$ ). Overall, the mice received a cumulative dose of $402 \mathrm{mg} /$ $\mathrm{kg}$ of DEN over a 50 day-span. They were euthanized after allowing for a 129-day span, corresponding to the carcinogenesis progression stage for histopathological analyses.

\section{Increased DEN toxicity during carcinogenesis promotion stage in $\operatorname{Per}^{\mathrm{m} / \mathrm{m}}$ mice}

The DEN daily dose had to be reduced from 15 to $12 \mathrm{mg} / \mathrm{kg}$, because of a rapid body weight loss during the carcinogenesis initiation stage, irrespective of Per 2 mutation $(8.9 \pm 1.3 \%$ in WT vs $10 \pm 1.4 \%$ in Per $\left.2^{\mathrm{m} / \mathrm{m}}, p=0.55\right)$. Following DEN re-exposure during the promotion stage, mean body weight loss reached a
A

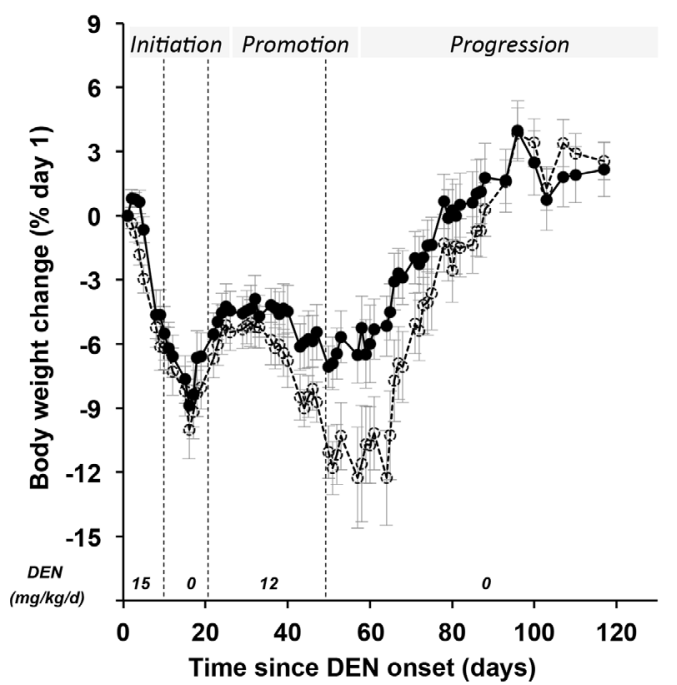

B
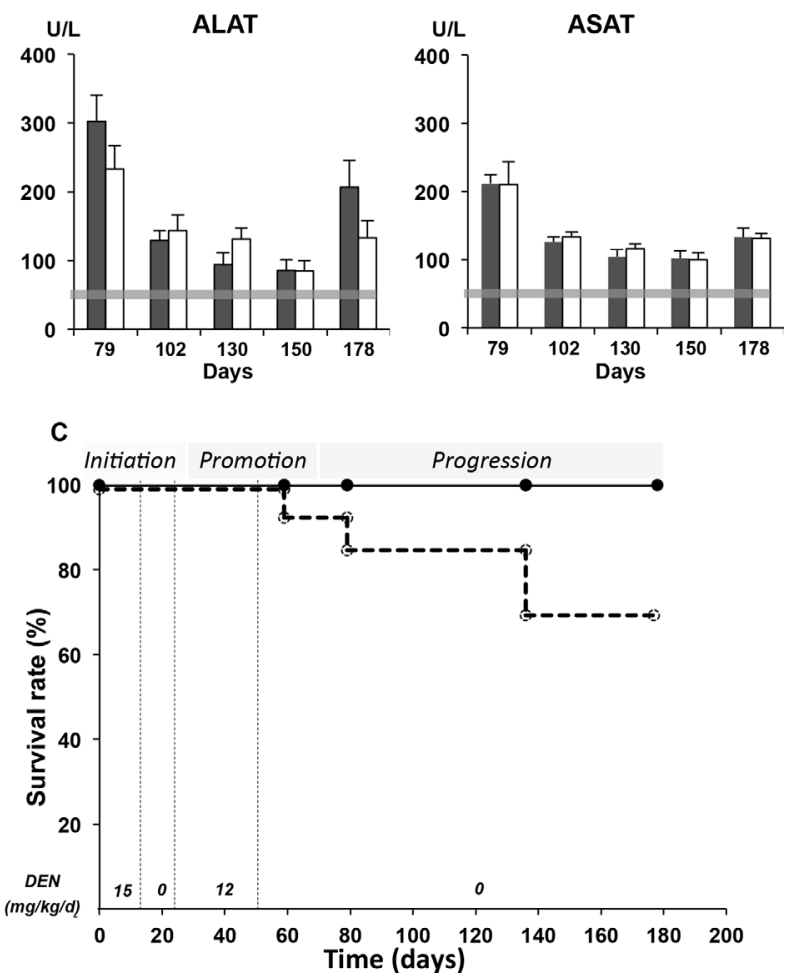

Figure 4: Systemic toxicity of DEN according to Per2 loss-of-function in the initiation, promotion and progression stages. A Relative body weight changes (mean \pm SEM) in WT (dark circles) and Per $2^{\mathrm{m} / \mathrm{m}}$ mice (open circles) during and after DEN exposure. The daily DEN doses ( $\mathrm{mg} / \mathrm{kg}$ ) are shown in italic, for corresponding exposure spans. B Histogram of serum levels of ALAT and ASAT (mean \pm SEM) after DEN exposure in WT (dark box) and $P e r 2^{\mathrm{m} / \mathrm{m}}$ (open box) mice in the progression stage. Mean \pm SEM ALAT and ASAT in untreated control mice is represented by the gray horizontal bar. C Survival rate in WT (dark circles) and Per $2^{\mathrm{m} / \mathrm{m}}$ (open circles) mice exposed to DEN over 180 days. 
second nadir 57 days after DEN treatment onset, which was $\sim$ twice as large in $P e r 2^{\mathrm{m} / \mathrm{m}}$ mice as compared to WT $(12.3 \pm 2.2 \%$ vs $6.5 \pm 1.3 \%, p$ from ANOVA < $0.001)$. Complete recovery of body weight was also slower in the $P e r 2^{\mathrm{m} / \mathrm{m}}$ as compared to WT (38 days vs 26 days) (Figure 4A). The aspartate levels of both alanine aminotransferase (ALAT) and aspartate aminotransferase (ASAT) were increased by up to six- and four-fold respectively $\sim 30$ days after completion of DEN exposure as compared to untreated controls. However, no difference was found according to Per 2 mutation over the 90-day span corresponding to the carcinogenesis progression stage (Figure 4B). No toxic death was encountered in the WT mice on DEN. In contrast, four $P e r 2^{\mathrm{m} / \mathrm{m}}$ mice died with severe liver alterations before study completion ( $p$ from log Rank=0.009) (Figure 4C). Two mice displayed histological evidence of liver inflammation, oval cell types, with major dysplasia and enlarged nuclei, associated with severe body weight loss $(37.4 \%)$ or ascites on days 59 and 79 respectively. The liver histology of both other mice revealed inflammatory foci. In addition, precancerous dysplasia was found for that mouse dead on day 136, while 4 liver cancer nodules were identified in the mouse that died on day 137. Only, this latter animal was counted among those that developed liver cancer.

\section{Major DEN-induced circadian disruption in $\operatorname{Per} 2^{\mathrm{m} / \mathrm{m}}$ mice}

The rest-activity and temperature circadian patterns were monitored in WT and $P e r 2^{\mathrm{m} / \mathrm{m}}$ mice for 5 days before DEN exposure, and throughout the initiation, promotion and progression stages of liver carcinogenesis using implanted telemetry sensors (Exp III), in order to assess the dynamics of circadian physiology disruption. Double-plot representations of both circadian biomarkers in individual mice revealed that the circadian disruption produced by DEN was transient for WT, and sustained for Per $2^{\mathrm{m} / \mathrm{m}}$ mice. The temperature rhythm appeared to be more sensitive to disruption as compared to rest-activity, and this was especially true during the progression carcinogenesis stage (Figure 5A and 5B). Moreover, a significant correlation was found between the circadian acrophases of both rhythms for WT mice $(\mathrm{r}=0.571$, $p=0.042$ ) but not for Per $2^{\mathrm{m} / \mathrm{m}}$ individuals ( $\mathrm{r}=0.197$, $p=0.518$ ). This finding supports the coupling of both physiological rhythms in WT and the occurrence of internal desynchronization in $P e r 2^{\mathrm{m} / \mathrm{m}}$ as a result of DEN exposure (Figure 5C).

Cosinor analysis further indicated that both restactivity and temperature patterns displayed periodic $24-\mathrm{h}$
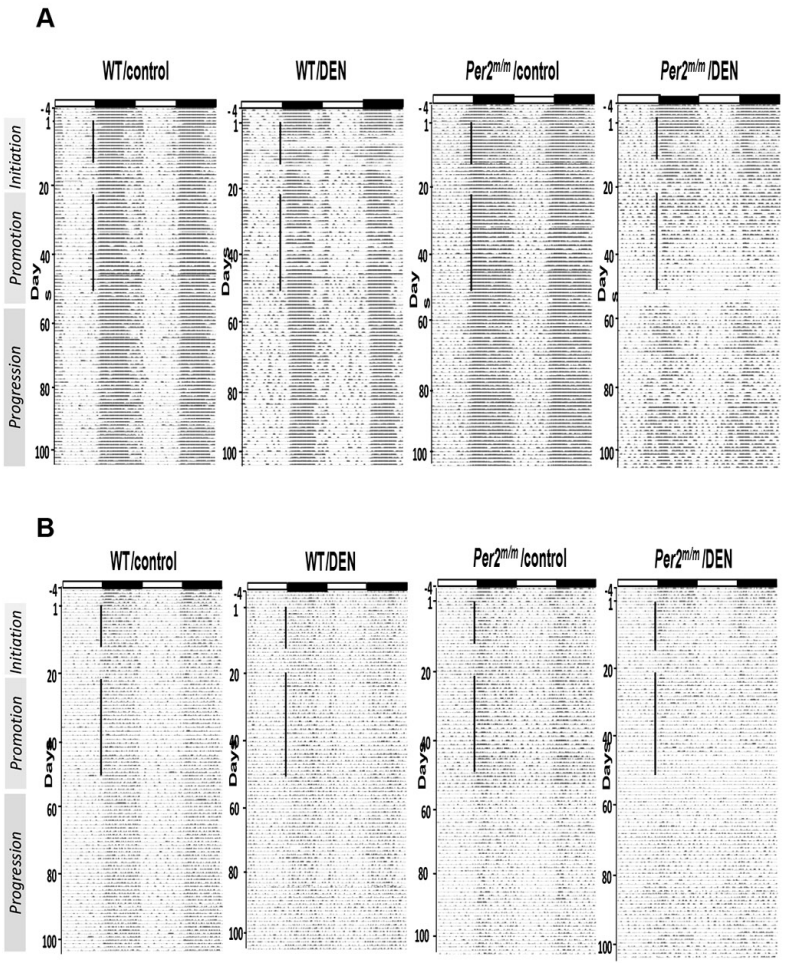
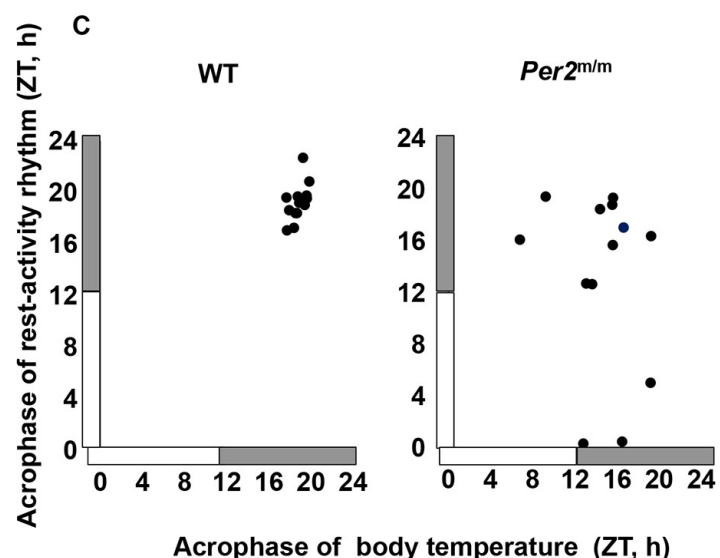

Acrophase of body temperature (ZT, h)

Figure 5: Examples of circadian physiology records in mice according to Per2 loss-of-function and DEN exposure for 50 days (initiation and promotion stages). Representative double-plots of temperature A. and activity B. rhythms according to Per 2 loss-of-function and DEN exposure. The vertical black lines indicate exposure to DEN or vehicle (control) for 7 weeks. C. Relation between acrophases of rest-activity and body temperature rhythms 7 weeks after DEN exposure onset in individual WT mice (left) and $P e r 2^{\mathrm{m} / \mathrm{m}}$ mice (right). Note robust coordination in WT and internal desynchronization in $P e r 2^{\mathrm{m} / \mathrm{m}}$. 
changes in $P e r 2^{\mathrm{m} / \mathrm{m}}$ and WT mice for the 5 days preceding DEN exposure. A 1-h phase advance was statistically validated in $P e r 2^{\mathrm{m} / \mathrm{m}}$ for both rest-activity (ZT16:07 vs ZT17:07, Hotelling t-test, $p=0.016)$ and body temperature (ZT16:39 vs ZT17:45, $p=0.001$ ) (Figure 6A). Although the baseline rest-activity amplitude was similar in both genotypes, that of body temperature was significantly lower in $P e r 2^{\mathrm{m} / \mathrm{m}}\left(0.7\right.$ vs $0.88^{\circ} \mathrm{C}$, Hotelling T test, $p<$ 0.001) (Figure 6B).

DEN suppressed the circadian rhythm in restactivity for $2 / 13 \mathrm{WT}(15 \%)$ and $8 / 13 \mathrm{Per}^{\mathrm{m} / \mathrm{m}}(62 \%)$, and that in body temperature for $2 / 13 P e r 2^{\mathrm{m} / \mathrm{m}}$ (15\%) during the initiation and/or the promotion stages. In the WT mice with circadian rhythms, DEN reduced $\sim$ three-fold the circadian amplitude of rest-activity and halved that of body temperature as compared to baseline. Such effect was achieved during the carcinogenesis initiation stage for both genotypes. During the promotion stage however, the amplitudes in rest-activity and body temperature deteriorated down to $1 / 9$ and $1 / 4$ of their respective baseline values in $P e r 2^{\mathrm{m} / \mathrm{m}}$ mice while no further changes were noticed in WT $(p<0.001)$ (Figure 6B). Over this 4 -week span, the circadian phase was delayed by $\sim 2 \mathrm{~h}$ for rest-activity and by $1 \mathrm{~h}$ for body temperature as compared to baseline in WT (Paired T-tests, $p=0.01$ and $p=0.003$, respectively). In contrast both of these rhythms were phase-advanced by $3 \mathrm{~h}$ and $2 \mathrm{~h}$ respectively in $P e r 2^{\mathrm{m} / \mathrm{m}}$ (Paired t-test, $p=0.04$ ) (Figure 6A).

\section{Accelerated progression of liver carcinogenesis in Per $2^{\mathrm{m} / \mathrm{m}}$ mice}

All the mice were euthanized and inspected for liver, lung, kidney or other tumor deposits 178 days after the onset of the DEN administration protocol, i.e. at an advanced carcinogenesis progression stage. Macroscopic

A
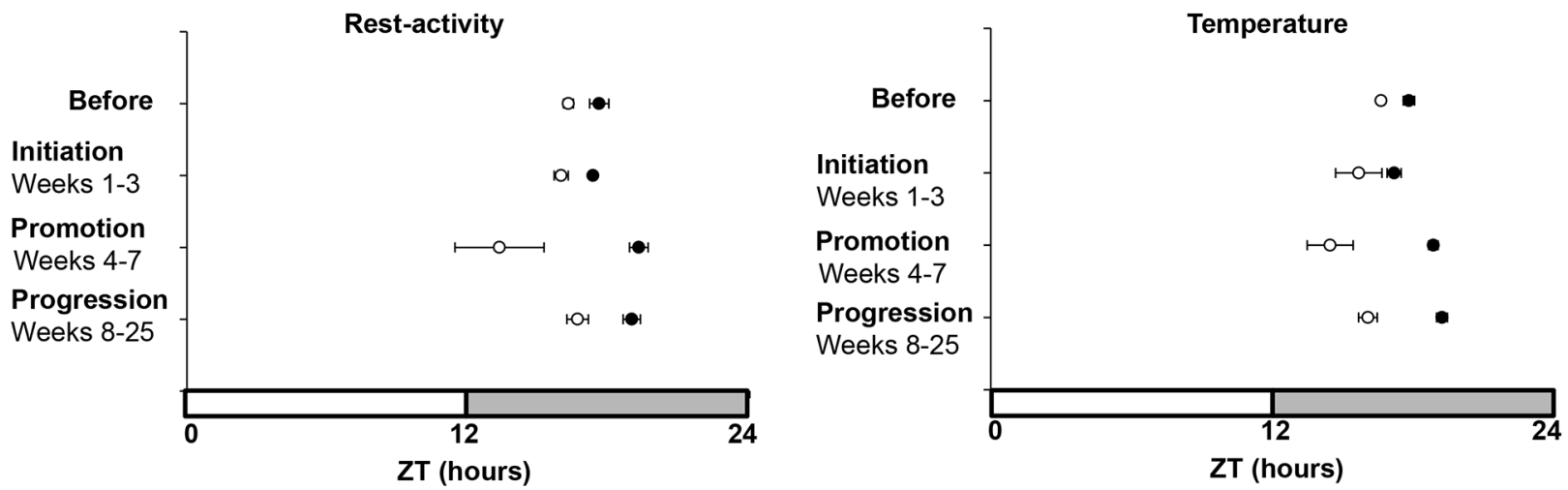

B
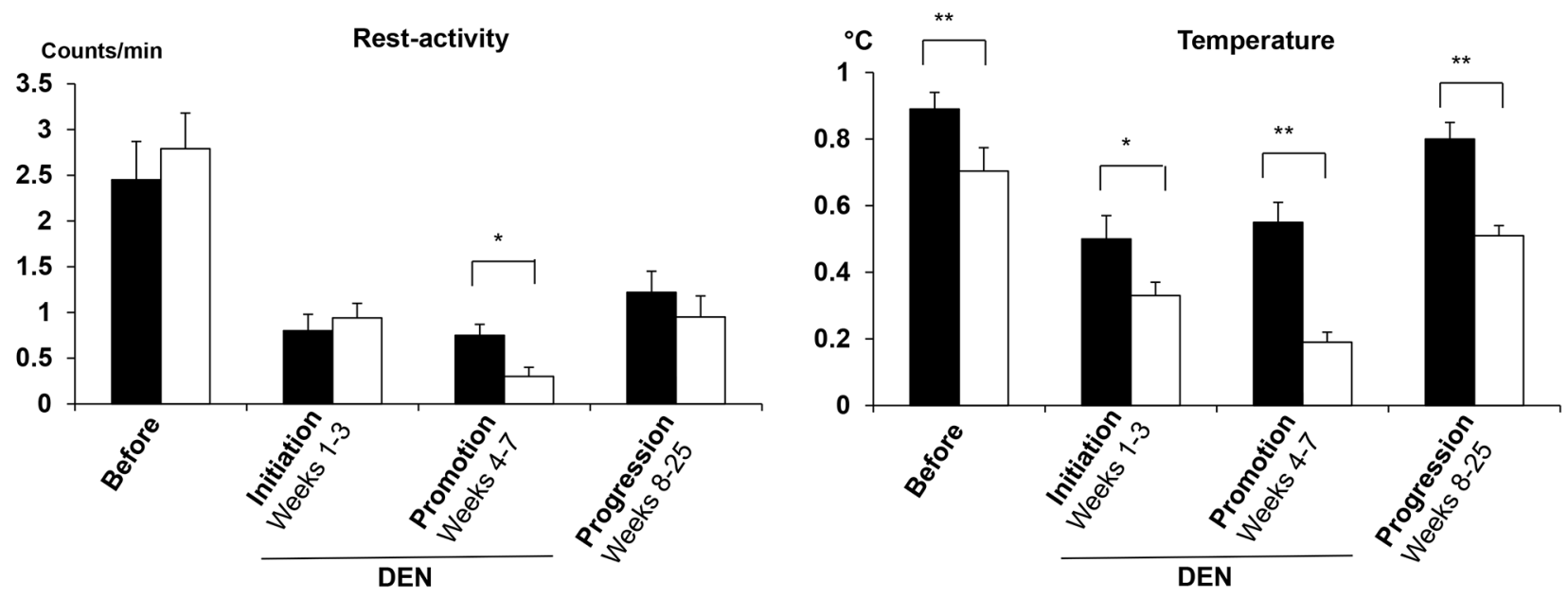

Figure 6: Dynamics of rest-activity and body temperature rhythms throughout liver carcinogenesis processes according to Per2 loss-of-function. A. Acrophase charts for rest-activity (left panel) and body temperature (right panel). Each acrophase (time of maximum in best-fitting 24-h cosine function) is displayed with its 95\% C.L. for WT (dark circles) and Per $2 \mathrm{~m} / \mathrm{m}$ (open circles) before, during the initial 3 weeks (weeks 1-3; initiation stage) and the subsequent 4 weeks on DEN (weeks 4-7; promotion stage), and after exposure (weeks 8-25; progression stage). B. Corresponding histograms of $24 \mathrm{~h}$ mean amplitudes with $95 \%$ C.L. for rest- activity (left panel) and body temperature (right panel) in WT (dark boxes) and Per $2 \mathrm{~m} / \mathrm{m}$ (open boxes). ${ }^{*} p<0.05 ; * * p<0.001$. 
tumor nodules were observed in all $P e r 2^{\mathrm{m} / \mathrm{m}}$ mice [Figure 7A (I)]. Histological analysis revealed the occurrence of minor or severe liver dysplasia [Figure 7A (II)], as well as both hepatocellular carcinoma (HCC) and cholangiocarcinoma (CCA) [Figure 7A (III-IV)], and pre-neoplastic nodules, inflammatory infiltrations and apoptotic hepatocytes. DEN further induced primary lung tubulo-papillary tumor in $5 \mathrm{WT}$ and $3 \mathrm{Per} 2^{\mathrm{m} / \mathrm{m}}$ with associated inflammatory foci. A single HCC metastasis was found in the kidney of a WT mouse.

Histopathological analysis was performed on three parallel transverse liver sections equispaced by $1 \mathrm{~mm}$. Liver tumor nodules, with diameters ranging from 1 to $11 \mathrm{~mm}$, were found in all the $P e r 2^{\mathrm{m} / \mathrm{m}}$ and in $77 \%$ of the WT mice. Histology revealed $\sim$ six times as many HCC as compared to CCA (69 vs 11), in both groups. The average number of tumors per animal, including HCC and CCA, was 3.7-fold as high in $P e r 2^{\mathrm{m} / \mathrm{m}}$ as compared to
WT (Figure 7B) (Kruskal-Wallis ANOVA, $p=0.01$ ). The number of tumor nodules ranged from 0 to 4 in WT mice, and from 1 to $10 \mathrm{in} P e r 2^{\mathrm{m} / \mathrm{m}}$. As a result, the proportion of mice with more than 2 tumor nodules was $\sim$ five-fold as high in $P e r 2^{\mathrm{m} / \mathrm{m}}$ as compared to WT (80\% vs $15 \%$, Fisher exact test, $p=0.003)$. The average number of HCC per mouse was 3.7-fold as high in $P e r 2^{\mathrm{m} / \mathrm{m}}$ mice as compared to WT (Kruskal-Wallis ANOVA, $p<0.001$ ) (Figure 7C).

\section{DISCUSSION}

To our knowledge, this study is the first one that reveals the crucial role of clock gene Per2 in liver carcinogenesis. DEN was used here as a carcinogen for both initiation and promotion of primary liver cancers in mice. Mutation of clock gene Per2 increased nearly fivefold the rate of mice with two or more primary liver cancers as compared to WT exposed to the same DEN
A
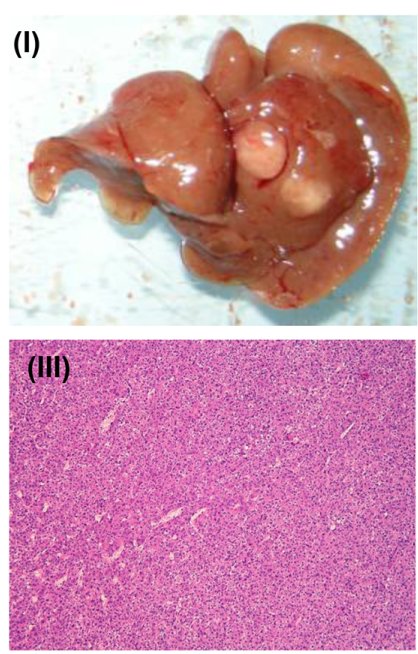

B

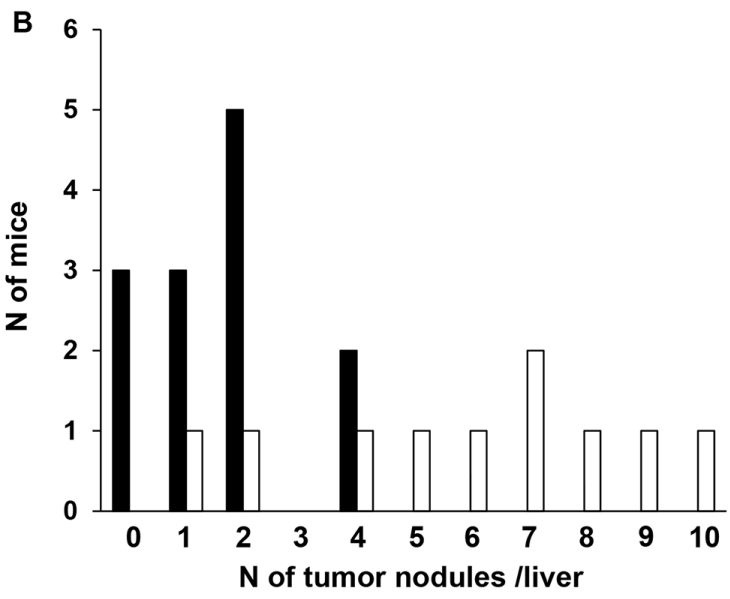

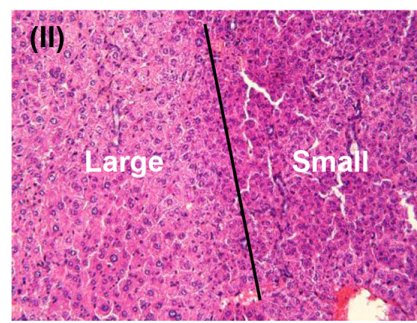

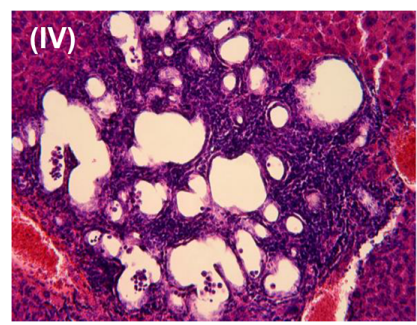

C

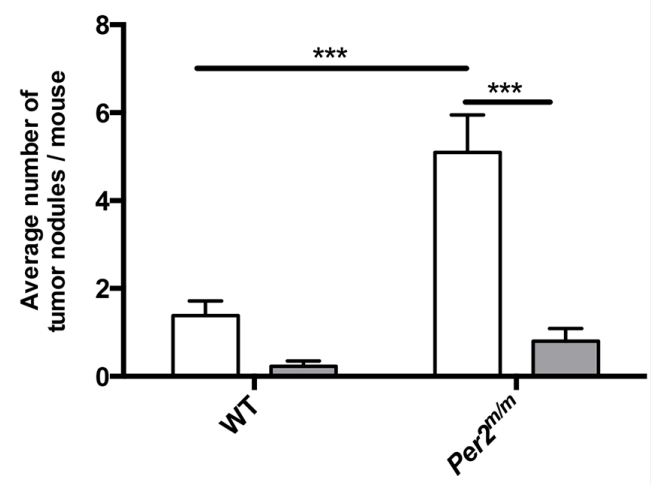

Figure 7: DEN-induced liver alterations according to Per2 loss-of-function found on day 178. A. Typical macroscopic view of a deeply reorganized liver with cancer nodules arising in a Per $2^{m / m}$ mouse (I); Typical microscopic view of large (left) or small (right) cell dysplasia coexisting in the same liver sample of a Per $2^{\mathrm{m} / \mathrm{m}}$ mouse and separated by a dark marker line (II); Microscopic view of hepatocarcinoma (III), and cholangiocarcinoma (IV). B. Number of tumor nodules per mouse liver in WT (black boxes) and Per $2^{\mathrm{m} / \mathrm{m}}$ (open boxes). C. Average number of hepatocarcinomas (open box) or cholangiocarcinomas (dark box) in WT and Per2 ${ }^{\mathrm{m} / \mathrm{m}}$ mice. ${ }^{* * *} p<0.001$. 
dose. Previous studies demonstrated that mutation or knock out of clock genes Per2, Cryl/Cry2 or Bmall also accelerated the development of lymphomas following whole body exposure to $\gamma$ radiations $[18,19]$. The clinical relevance of our findings is illustrated by the fact that Per2 expression was also decreased in human HCC as well as in other human cancers, as compared to the corresponding healthy tissues [27, 28]. Furthermore, the down regulation of Per 2 expression in human cancers was usually associated with poor patient outcomes [29]. In contrast, the overexpression of Per2 inhibited proliferation and arrested cell cycling in cancer cell lines, thus supporting the negative growth-regulatory properties of Per2 [16].

Circadian disruption resulting from an altered light-dark environment had been previously identified as a promoter of liver carcinogenesis in rats and mice [22, 23]. In contrast, the current study showed that initiation, promotion and progression stages of liver carcinogenesis were regulated by Per2. Indeed, Per2 mutation resulted in profound circadian disruption of selected gene and protein expressions during the initiation stage, although no apparent difference was observed at histopathologic analysis of liver obtained after 17 days on DEN. Prior to DEN exposure, Per 2 mutation was already associated with profound molecular circadian disruption in liver despite regular lightdark exposure. Thus, both 24-h expressions and circadian amplitudes of Bmall and Cryl were markedly reduced. In addition, a 2- to 5-h phase advance was shown for clock and cell cycle-related genes, supporting an alteration of the clock-cell cycle coupling [10] in Per $2^{\mathrm{m} / \mathrm{m}}$. The 24-h mean mRNA expression of $c-M y c$ was doubled in the liver of untreated $P e r 2^{\mathrm{m} / \mathrm{m}}$ as compared to WT mice in the current study. This was related to the demonstrated role of Bmall as a repressor of proto-oncogene $c-M y c$ through binding to its $\mathrm{P} 1$ promoter [18].

The several-fold higher rate of liver cancers in $P e r 2^{\mathrm{m} / \mathrm{m}}$ mice as compared to WT at $\sim 6$ months after the beginning of treatment was preceded by the up-regulation of several critical liver carcinogenesis pathways at 17 days after DEN administration onset. Thus, molecular markers of proliferation, genomic instability, apoptosis, and inflammation were significantly deregulated in $P e r 2^{\mathrm{m} / \mathrm{m}}$, as compared to WT, despite apparently similar extent of histological liver inflammation. DEN exposure further significantly dampened the circadian transcription amplitude of Bmall, Rev-erb $\alpha, C r y 1$, and Clock in Per $2^{\mathrm{m} / \mathrm{m}}$ as compared to WT. This severe alteration of the liver clock translated into the up-regulation and/or the circadian deregulation of the selected molecular markers of cellular proliferation including $c-M y c$, Ccnbl, Weel, and K-ras. DEN exposure had less prominent effects on the 24-h expression patterns of the selected genomic instability genes ATM and P53 both in WT and Per $2^{\mathrm{m} / \mathrm{m}}$. In contrast, apoptosis induction was reported in cultured mouse primary hepatocytes exposed to DEN for $24 \mathrm{~h}$, an effect which was suppressed in Clock mutant hepatocytes [30].
DEN exposure in the initiation stage has long been known as inducing hepatocyte deaths, activation of NF- $\mathrm{KB}$ pathway in liver macrophages, and liver inflammation [31, 32]. In our study, histologic lesions were documented at 17 days, with occasional deaths, occurring in $P e r 2^{\mathrm{m} / \mathrm{m}}$ mice over the subsequent 3 months. IL- 6 and TNF- $\alpha$ proteins were significantly increased in $P e r 2^{\mathrm{m} / \mathrm{m}}$ as compared to WT, while their 24-h amplitudes were less in $P e r 2^{\mathrm{m} / \mathrm{m}}$. During the initiation of carcinogenesis, NF- $\mathrm{KB}$ overexpression accelerates cellular proliferation and inhibits apoptosis through the activation of $I L-6$ and $T N F-\alpha$ genes $[33,34]$. Indeed, $\mathrm{Per}^{-/}$mice, a construct which differed from $P e r 2^{\mathrm{m} / \mathrm{m}}$ by the lack of any PER2 protein, also displayed increased $T N F-\alpha$ expression jointly with liver cholestasis or fibrosis, in response to physical liver injury [35].

DEN metabolism also involves clock-controlled pathways, which were not explored here. DEN was administered at ZT11, near the end of the light span, coincidently with the physiologic peak in plasma corticosterone in WT mice. This hormone triggers the bioactivation of DEN by hepatic microsomes, thus potentiates its liver toxicity [36]. DEN is mainly bioactivated into ethyldiazonium ion by CYP2E1 and CYP2A5 in mouse liver [24]. Cyp2e1 displayed mRNA and protein circadian variations in mouse liver, with peak expression occurring in the late light span (ZT10), for mRNA, and in the early dark span (ZT15), for protein. Moreover, Cyp2e1 activation was suppressed by PER2 [37]. Thus, Per2 mutation would expectedly enhance DEN bioactivation. However, clock-controlled glutathionerelated genes in liver also peaked in the late light span, resulting in highest levels of reduced glutathione near ZT15 [38]. This supported highest DEN detoxification near the middle of the activity phase of mouse restactivity circadian rhythm. Taken together, the available data revealed that DEN bioactivation and detoxification pathways were both controlled by the circadian clock in mouse liver. However, these opposite processes followed a coincident circadian pattern, thus suggesting their respective effects on DEN could antagonize each other. The plasma levels of liver ASAT and ALAT were increased up to six-fold as compared to controls at the beginning of the progression carcinogenesis stage, then decreased over about 2 months, then increased again. These changes reflected the complex dynamics in the underlying DENinduced chronic cirrhosis and fibrosis, which constitute the grounds on which liver cancers develop. Since no difference was found according to Per2 mutation, this supports the hypothesis that Per2 played a critical role for the development of liver cancers rather than for that of chronic liver disease.

The deleterious effects of DEN on circadian clocks during carcinogenesis initiation was also documented here using circadian biomarkers. Both rest-activity and core body temperature rhythms displayed severe disruption in WT mice, while an internal desynchronization was 
found in $P e r 2^{m / m}$. We hypothesized that the release of inflammatory cytokines resulting from initial acute liver damage could in turn disrupt circadian physiology, thus depriving molecular clocks and clock-controlled pathways in peripheral tissues from resetting time cues. Such desynchronization of molecular clocks could further alter xenobiotic metabolism and detoxification, and favor carcinogenic processes, and even more so in clockdefective $\operatorname{Per} 2^{m / m}$ mice $[39,40]$. Circadian disruption remained consistently worse in $P e r 2^{\mathrm{m} / \mathrm{m}}$ as compared to WT mice during both the promotion and the progression stages of liver carcinogenesis. Such profound and sustained alterations in the circadian timing system thus contributed to enhance cancer development throughout all three carcinogenesis stages.

In summary, the loss of function of Per 2 critically deregulated the circadian clock and clock-controlled pathways, whose alteration contributed to three cancer hallmarks, within the initial 3 weeks of DEN exposure. As a result, the formation of liver cancers was increased by up to four-fold, six months after the onset of carcinogen exposure, Clock gene Per2 could thus represent a promising target for liver cancer prevention and therapy.

\section{MATERIALS AND METHODS}

\section{Mice}

Animal experiments were performed under the guidelines approved for animal experimental procedures by the French Ethical Committee (decree 87-848). Male $129 \mathrm{SvEv}^{\mathrm{Brd}} / \mathrm{C} 57 \mathrm{BL} / 6$-Tyrc-Brd mice with or without constitutive Per 2 mutation were used for all experiments [17]. The $P e r 2^{\mathrm{m} / \mathrm{m}}$ mice and their WT counterpart were a generous gift from Urs Albrecht (Freiburg, Switzerland). They were kept at $21^{\circ} \mathrm{C}$ to $23^{\circ} \mathrm{C}$ in chronobiologic facilities, with light intensity at cage level ranging from 240 to 580 lux according to cage location. Mice were aged 8 to 14 weeks upon inclusion in each experiment, with $85 \%$ of them being 10-14 weeks old (Supplementary Table S1). They were stratified according to age, then allocated to treatment group, and synchronized with an alternation of $12 \mathrm{~h}$ of light (L) and $12 \mathrm{~h}$ of darkness (D) (LD 12:12) for at least 3 weeks before starting and during each experiment, and had free access to food and water. Zeitgeber Time (ZT) 0 corresponded to light onset, while ZT12 corresponded to dark onset.

\section{Experimental design}

The study involved three experiments (Exp). Exp I aimed at jointly determining the regulatory role of Per2 gene on circadian clock, proliferation, genomic instability, and inflammation both in the absence of DEN administration and during the carcinogenesis initiation stage, after 17-day DEN treatment. Thirty WT and 30
Per $2^{\mathrm{m} / \mathrm{m}}$ mice were euthanized at 6 time points, located 4 h apart, i.e. ZT3, 7, 11, 15, 19, and 23. Blood $(200 \mu \mathrm{L})$ was sampled on heparin in order to determine plasma corticosterone concentration. A liver lobe was obtained and frozen in liquid nitrogen, then kept at $-80{ }^{\circ} \mathrm{C}$. Total RNA and proteins were extracted from each mouse liver for the determination of selected gene mRNA expressions, as well as selected cytokine concentrations.

Exp II assessed the role of Per2 on liver pathology (IIA) and several main molecular mechanisms (IIB) during the initiation stage of liver carcinogenesis. For Exp IIA, $6 \mathrm{WT}$ and $6 \mathrm{Per} 2^{\mathrm{m} / \mathrm{m}}$ mice received daily intraperitoneal injection (i.p) of DEN (Sigma-Aldrich, Saint Quentin Fallavier, France) at ZT11 for 17 days (cumulative dose of $195 \mathrm{mg} / \mathrm{kg}$ ). Twenty-four hours after the last injection, mice were sacrificed and livers were removed for histological studies.

For Exp IIB, $30 \mathrm{WT}$ and $42 \mathrm{Per} 2^{\mathrm{m} / \mathrm{m}}$ mice, received a cumulative dose of $195 \mathrm{mg} / \mathrm{kg}$ DEN (15 mg/kg/d i.p. at ZT11) over a 17-day span. Five WT and 5 Per $2^{\mathrm{m} / \mathrm{m}}$ mice underwent circadian monitoring of rest-activity and body temperature for 5 days before and during DEN exposure. Plasma corticosterone concentration and selected liver gene mRNA expressions, as well as liver IL-6 and TNF- $\alpha$ concentrations were determined in $5 \mathrm{WT}$ and $7 \mathrm{Per} 2^{\mathrm{m} / \mathrm{m}}$ every $4 \mathrm{~h}$ for $24 \mathrm{~h}$.

Exp III determined the role of Per2 mutation in DEN-induced liver carcinogenesis, involving all three stages. Thirteen $\mathrm{WT}$ and 13 Per $2^{\mathrm{m} / \mathrm{m}}$ mice received a cumulative dose of $402 \mathrm{mg} / \mathrm{kg}$ of DEN, using a 5-days on and 2-days off schedule over an overall exposure duration of 50 days. Two control mice per genotype received $0.9 \%$ $\mathrm{NaCl}$, solution. DEN was injected i.p. to mice aged 12-14 weeks at ZT11 from day 1 to 12 at a daily dose of $15 \mathrm{mg} /$ $\mathrm{kg}$, followed with a 9-day DEN-free interval, and DEN (12 mg/kg daily) from day 22 to 50 . Body weight was recorded daily at ZT11 before each injection for 50 days, then every 3 days for 128 days. Mortality was checked daily. Blood $(100 \mu \mathrm{l})$ was sampled from the retro-orbital sinus on days $79,102,130,150$, and 178 , i.e. during the carcinogenesis progression stage, for the determinations of ASAT and ALAT concentrations, with a Synchron LX20 Clinical System (Beckman Coulter, Villepinte, France). All the mice underwent monitoring of restactivity and core body temperature for 5 days before DEN exposure, throughout DEN treatment, and subsequently until experiment completion. Mice were euthanized 178 days after DEN administration onset for pathology and histology studies.

\section{Circadian rest-activity and core body temperature rhythm monitoring}

Mice underwent i.p. implantation of a telemetry sensor and radiotransmitter under isoflurane anesthesia 2 weeks before starting effective recording of locomotor 
activity and body temperature every $10 \mathrm{~min}$ (Physio Tel, TA 10 TA-F20, Data Sciences, St. Paul, Minnesota) (39). For Exp II, mice were monitored for 17 days before DEN treatment onset, and during the 17-day carcinogenesis initiation stage. For Exp III, body temperature and rest-activity were recorded for 5 days before DEN administration and until completion of experiment, i.e. 178 days after DEN exposure onset.

\section{Pathology and histological analyses}

Gross pathology examination was performed on the $12 \mathrm{WT}$ and $P e r 2^{\mathrm{m} / \mathrm{m}}$ mice for Exp IIA and on all the 26 DEN-exposed WT and Per $2^{\mathrm{m} / \mathrm{m}}$ mice included in Exp III, in order to identify any macroscopic abnormality either after intercurrent death or following sacrifice 17 days for Exp IIA and 178 days for Exp III after DEN exposure onset. Organs sampled involved whole liver in Exp IIA and whole liver, both lungs, and both kidneys in Exp III. They were removed immediately, then fixed in $4 \%$ formaldehyde for $24 \mathrm{~h}$, then dehydrated and embedded into paraffin. Three $4 \mu \mathrm{m}$-thick serial histological sections were obtained $1 \mathrm{~mm}$ apart in each liver, and stained with hematoxylin-eosin-saffron. A senior pathologist (C.G.) carefully examined each slide under a light microscopic for counting all detectable tumor nodules, for measuring their diameter, and for identifying their histological characteristics, without any information on genotype or experimental conditions.

\section{RNA extraction, cDNA synthesis, and RT-qPCR}

Total liver RNA was isolated from the frozen tissue specimens with an acidic solution containing acid guanidinium thiocyanate, phenol, and chloroform (41). cDNA were synthesized using SuperScript Reverse Transcriptase kit (Invitrogen, Cergy Pontoise -France). Quantitative PCR (qPCR) was performed in a light cycler system instrument using Light Cycler 480 SYBR Green I Master kit (Roche, France). All primers were obtained from Invitrogen Life Technologies (Supplementary Table S2).

\section{Plasma corticosterone and liver cytokines determinations}

Blood $(200 \mu \mathrm{L})$ was sampled on heparin from the retro-orbital sinus prior to mouse euthanizing. Blood was centrifuged at $5000 \mathrm{rpm}$, plasma extracted and frozen at $-80{ }^{\circ} \mathrm{C}$. Plasma corticosterone concentration was determined with ELISA (Enzo Life Sciences, Villeurbanne-France). Data were expressed as $\mathrm{ng} / \mathrm{mL}$ of plasma.

Liver proteins were extracted with an established buffer (Tris $20 \mathrm{mM}$, EDTA $2 \mathrm{mM}$, EGTA $5 \mathrm{mM}$, DTT $0.5 \mathrm{mM}$, $\mathrm{NaCl} 100 \mathrm{Mm}$, and Triton 0.1\%). The liver concentrations were determined with "BioPhotometer" for total proteins, and with commercially available ELISA kits (Invitrogen, Cergy Pontoise-France) for IL-6 and TNF- $\alpha$. Cytokine concentrations in liver were expressed as $\mathrm{pg} / \mathrm{mg}$ of proteins.

\section{Statistical analyses}

Mean \pm standard error of the mean (SEM) were computed for all quantitative data according to sampling time (ZT), genotype (WT vs Per $2^{\mathrm{m} / \mathrm{m}}$ ), experimental condition (DEN exposure vs no DEN). Group comparisons involved multiple way analyses of variance (ANOVA) with Scheffé's contrast tests. Incidence data were compared with Chi-Square or Exact Fischer test.

Survival curves were compared with log-rank. Time series were first examined with chronogram inspection. Rest-activity and temperature time series were analyzed with spectral analysis through Fast Fourier Transform in order to determine the occurrence of a dominant period $\tau$ in the circadian domain. Cosinor analyses with $\tau=24 \mathrm{~h}$ were performed for all the $24 \mathrm{~h}$ time series in order to determine mesor ( $24 \mathrm{~h}$ mean), amplitude (half the difference between maximum and minimum value of fitted cosine function) and acrophase (timing of maximum, referred to ZT0). All parameters were computed with their 95\% Confidence Limits. Statistical significance required a $P$ value $<0.05$. All statistical analyses were performed using SPSS statistical analysis software version 18 (Statistical Package for Social Sciences, Chicago, IL, USA).

\section{Abbreviations}

WT, wild-type; DEN, diethylnitrosamine; HCC, hepatocellular carcinoma; Per2, Period 2; Cry, cryptochrome; mRNA, messenger RNA; CTS, circadian timing system; CCNB1, cyclin B1; $\mathrm{Bcl} 2$, B cell lymphoma 2; Per $2^{\mathrm{m} / \mathrm{m}}$, Per2 mutant mice; ZT, Zeitgeber time; qPCR, quantative polymerase chain reaction; SEM, standard error of the mean; ALAT, alanine aminotransferase; ASAT, aspartate aminotransferase; CCA, cholangiocarcinoma.

\section{CONFLICTS OF INTEREST}

The authors declare that they have no conflict of interest.

\section{GRANT SUPPORT}

This work was supported by grant ANR 2009SYSB-002-01-04 (ERASySBio+ and FP7) to the C5Sys project, the Association pour la Recherche sur le Temps Biologique et la Chronothérapie (ARTBC International, Paul Brousse hospital, Villejuif, France) and Cancer Research UK grant C53561/A19933. 


\section{Authors' contributions}

A.M.: Conceived and designed study; Performed research; Analyzed data; Wrote the paper

E.F.: Conceived and designed study

C.G.: Contributed specific pathology methods

A.O.: Analyzed data; Wrote the paper

F.L.: Conceived and designed study; Analyzed data;

Wrote the paper

\section{REFERENCES}

1. Mancuso A. Management of hepatocellular carcinoma: Enlightening the gray zones. World J Hepatol. 2013; 5:302-310.

2. Chou CF, Zhu X, Lin YY, Gamble KL, Garvey WT and Chen CY. KSRP is critical in governing hepatic lipid metabolism through controlling Per2 expression. J Lipid Res. 2015; 56:227-240.

3. Weigl Y, Ashkenazi IE and Peleg L. Rhythmic profiles of cell cycle and circadian clock gene transcripts in mice: a possible association between two periodic systems. J Exp Biol. 2013; 216:2276-2282.

4. Lee JS, Grisham JW and Thorgeirsson SS. Comparative functional genomics for identifying models of human cancer. Carcinogenesis. 2005; 26:1013-1020.

5. Vollmers C, Schmitz RJ, Nathanson J, Yeo G, Ecker JR and Panda S. Circadian oscillations of protein-coding and regulatory RNAs in a highly dynamic mammalian liver epigenome. Cell Metab. 2012; 16:833-845.

6. Schmutz I, Albrecht U and Ripperger JA. The role of clock genes and rhythmicity in the liver. Mol Cell Endocrinol. 2012; 349:38-44.

7. Partch CL, Green CB and Takahashi JS. Molecular architecture of the mammalian circadian clock. Trends Cell Biol. 2013.

8. Mohawk JA, Green CB and Takahashi JS. Central and peripheral circadian clocks in mammals. Annu Rev Neurosci. 2012; 35:445-462.

9. Johnson $\mathrm{CH}$. Circadian clocks and cell division: what's the pacemaker? Cell Cycle. 2010; 9:3864-3873.

10. Feillet C, Krusche P, Tamanini F, Janssens RC, Downey MJ, Martin P, Teboul M, Saito S, Levi FA, Bretschneider T, van der Horst GT, Delaunay F and Rand DA. Phase locking and multiple oscillating attractors for the coupled mammalian clock and cell cycle. Proc Natl Acad Sci U S A. 2014; 111:9828-9833.

11. Goldbeter A, Gérard C, Gonze D, Leloup JC and Dupont G. Systems biology of cellular rhythms. FEBS Lett. 2012; 586:2955-2965

12. Kornmann B, Schaad O, Bujard H, Takahashi JS and Schibler U. System-driven and oscillator-dependent circadian transcription in mice with a conditionally active liver clock. PLoS Biol. 2007; 5:e34.
13. Albrecht U, Bordon A, Schmutz I and Ripperger J. The multiple facets of Per2. Cold Spring Harb Symp Quant Biol. 2007; 72:95-104.

14. Hua H, Wang Y, Wan C, Liu Y, Zhu B, Yang C, Wang X, Wang Z, Cornelissen-Guillaume G and Halberg F. Circadian gene mPer2 overexpression induces cancer cell apoptosis. Cancer Sci. 2006; 97:589-596.

15. Sun CM, Huang SF, Zeng JM, Liu DB, Xiao Q, Tian WJ, Zhu XD, Huang ZG and Feng WL. Per2 inhibits k562 leukemia cell growth in vitro and in vivo through cell cycle arrest and apoptosis induction. Pathol Oncol Res. 2010; 16:403-411.

16. Miyazaki K, Wakabayashi M, Hara $\mathrm{Y}$ and Ishida $\mathrm{N}$. Tumor growth suppression in vivo by overexpression of the circadian component, PER2. Genes Cells. 2010; 15:351-358

17. Zheng B, Larkin DW, Albrecht U, Sun ZS, Sage M, Eichele $\mathrm{G}$, Lee CC and Bradley A. The mPer2 gene encodes a functional component of the mammalian circadian clock. Nature. 1999; 400:169-173.

18. Fu L, Pelicano H, Liu J, Huang P and Lee C. The circadian gene Period2 plays an important role in tumor suppression and DNA damage response in vivo. Cell. 2002; 111:41-50.

19. Lee S, Donehower LA, Herron AJ, Moore DD and Fu L. Disrupting circadian homeostasis of sympathetic signaling promotes tumor development in mice. PLoS One. 2010; 5:e10995.

20. Li XM, Mohammad-Djafari A, Dumitru M, Dulong S, Filipski E, Siffroi-Fernandez S, Mteyrek A, Scaglione F, Guettier C, Delaunay F and Levi F. A circadian clock transcription model for the personalization of cancer chronotherapy. Cancer Res. 2013; 73:7176-7188.

21. Filipski E and Levi F. Circadian disruption in experimental cancer processes. Integr Cancer Ther. 2009; 8:298-302.

22. van den Heiligenberg S, Deprés-Brummer P, Barbason H, Claustrat B, Reynes M and Lévi F. The tumor promoting effect of constant light exposure on diethylnitrosamineinduced hepatocarcinogenesis in rats. Life Sci. 1999; 64:2523-2534.

23. Filipski E, Subramanian P, Carriere J, Guettier C, Barbason $\mathrm{H}$ and Levi F. Circadian disruption accelerates liver carcinogenesis in mice. Mutat Res. 2009; 680:95-105.

24. Verna L, Whysner $\mathrm{J}$ and Williams GM. N-nitrosodiethylamine mechanistic data and risk assessment: bioactivation, DNA-adduct formation, mutagenicity, and tumor initiation. Pharmacol Ther. 1996; 71:57-81.

25. Williams GM, Iatropoulos MJ, Wang CX, Ali N, Rivenson A, Peterson LA, Schulz C and Gebhardt R. Diethylnitrosamine exposure-responses for DNA damage, centrilobular cytotoxicity, cell proliferation and carcinogenesis in rat liver exhibit some non-linearities. Carcinogenesis. 1996; 17:2253-2258. 
26. Karin M and Greten FR. NF-kappaB: linking inflammation and immunity to cancer development and progression. Nat Rev Immunol. 2005; 5:749-759.

27. Lin YM, Chang JH, Yeh KT, Yang MY, Liu TC, Lin SF, $\mathrm{Su}$ WW and Chang JG. Disturbance of circadian gene expression in hepatocellular carcinoma. Mol Carcinog. 2008; 47:925-933.

28. $\mathrm{Fu} \mathrm{L}$ and Kettner NM. The circadian clock in cancer development and therapy. Prog Mol Biol Transl Sci. 2013; 119:221-282.

29. Ortiz-Tudela E, Mteyrek A, Ballesta A, Innominato PF and Lévi F. Cancer chronotherapeutics: experimental, theoretical, and clinical aspects. Handb Exp Pharmacol. 2013; :261-288.

30. Matsunaga N, Kohno Y, Kakimoto K, Hayashi A, Koyanagi $\mathrm{S}$ and Ohdo S. Influence of CLOCK on cytotoxicity induced by diethylnitrosamine in mouse primary hepatocytes. Toxicology. 2011; 280:144-151.

31. Zeh HJ and Lotze MT. Addicted to death: invasive cancer and the immune response to unscheduled cell death. J Immunother. 2005; 28:1-9.

32. Sun B and Karin M. Inflammation and liver tumorigenesis. Front Med. 2013; 7:242-254.

33. Pikarsky E, Porat RM, Stein I, Abramovitch R, Amit S, Kasem S, Gutkovich-Pyest E, Urieli-Shoval S, Galun $\mathrm{E}$ and Ben-Neriah Y. NF-kappaB functions as a tumour promoter in inflammation-associated cancer. Nature. 2004; 431:461-466.
34. Prasad S, Ravindran J and Aggarwal BB. NF-kappaB and cancer: how intimate is this relationship. Mol Cell Biochem. 2010; 336:25-37.

35. Chen P, Kakan X, Wang S, Dong W, Jia A, Cai C and Zhang J. Deletion of clock gene Per2 exacerbates cholestatic liver injury and fibrosis in mice. Exp Toxicol Pathol. 2013; 65:427-432.

36. Gielen JE, Van Cantfort $\mathrm{J}$ and Kremers P. Genetic and hormonal regulation of steroid hydroxylases and drug metabolizing enzymes in rat liver. Arch Toxicol. 1976; 36:255-266.

37. Matsunaga N, Ikeda M, Takiguchi T, Koyanagi S and Ohdo $\mathrm{S}$. The molecular mechanism regulating 24-hour rhythm of CYP2E1 expression in the mouse liver. Hepatology. 2008; 48:240-251.

38. Xu YQ, Zhang D, Jin T, Cai DJ, Wu Q, Lu Y, Liu J and Klaassen CD. Diurnal variation of hepatic antioxidant gene expression in mice. PLoS One. 2012; 7:e44237.

39. Filipski E, Innominato PF, Wu M, Li XM, Iacobelli S, Xian LJ and Levi F. Effects of light and food schedules on liver and tumor molecular clocks in mice. J Natl Cancer Inst. 2005; 97:507-517.

40. Levi F, Okyar A, Dulong S, Innominato PF and Clairambault J. Circadian timing in cancer treatments. Annu Rev Pharmacol Toxicol. 2010; 50:377-421.

41. Chomczynski P and Sacchi N. Single-step method of RNA isolation by acid guanidinium thiocyanate-phenolchloroform extraction. Anal Biochem. 1987; 162:156-159. 